\title{
Drowning Rates in the Newly Independent States \& Russian Federation: A Call for Research and Action
}

\author{
Huseyin Naci* and Timothy D. Baker
}

Department of International Health, Johns Hopkins Bloomberg School of Public Health. 615 N. Wolfe Street, Baltimore, MD 21205, USA

\begin{abstract}
Drowning is the second leading cause of unintentional injury deaths worldwide after road traffic injury deaths, claiming approximately 450,000 lives every year. Overall male drowning rates in the Newly Independent States and Russian Federation are dramatically higher than the rates in Western European countries; the highest male drowning rate in WHO Euro region, drowning rate in Belarus, is 50 times higher than the lowest, the drowning rate in the United Kingdom. 1-4 age group male drowning rate in Turkmenistan is alarmingly high. More research is needed to determine the risk factors of child and adult drowning in each of the Newly Independent States and Russian Federation.
\end{abstract}

Keywords: Drowning, Russia, newly independent states, child drowning.

Drowning is a major worldwide public health problem. The World Health Organization (WHO) estimated that, in 2000, worldwide 450,000 people drowned [1]. Thus, drowning is the second leading cause of unintentional injury death worldwide following road traffic injuries. The burden of drowning differs dramatically among countries; $97 \%$ of the drowning deaths occur in low- and middle-income countries [1]. In low- and middle-income countries, the majority of drowning fatalities are not associated with recreation or leisure but with occupation and everyday activities.

\section{THE EAST-WEST GAP IN DROWNING RATES IN THE EUROPEAN REGION}

The WHO Statistical Information System (WHOSIS) reports that drowning mortality rate for Europe is lower than other regions. However, it is important to note that regional drowning rates obscure significant differences among individual countries; the extraordinarily high drowning-related mortality rates in the newly independent states of the former USSR and Russian Federation are offset by the very low drowning rates from western Europe, resulting in an overall low drowning mortality rate for the WHO Europe region.

Since male drowning outnumbers females dramatically, this article focuses on male drowning. The data on countryspecific drowning rates for males shows that there are dramatic differences between countries' drowning rates. The countries with the highest drowning-related mortality rates (rates higher than 10/100,000), Belarus, Russian Federation, Lithuania, Latvia, Ukraine, Kazakhstan, Turkmenistan, and Estonia have similar GDP per capita values and all are newly independent states (Fig. 1). Belarus has the highest overall rate of drowning for males with $27 / 100,000$ people, more than 50 times the lowest drowning-related mortality rate in Europe (United Kingdom 0.5/100,000 people) [1].

*Address correspondence to this author at the Department of International Health, Johns Hopkins Bloomberg School of Public Health, 615 N. Wolfe Street, Baltimore, MD 21205, USA;

Tel: (202) 746-7900; E-mail: hnaci@jhsph.edu
Among countries with less than US \$20,000 GDP per capita, all nine countries that have drowning rates higher than 10/100,000 population are newly independent states and Russian Federation. Furthermore the high rates in the Russian Federation and those newly independent states have persisted for the last ten years of record. Seven central European countries that have less than US $\$ 20,000$ GDP per capita have drowning rates that are below $5 / 100,000$ population.

There are, however, dramatic variations among the newly independent states as well. Armenia and Georgia, for example, have very low rates with 2.1 and 1.9 per 100,000 people, respectively. These two countries share similar GDP per capita values and a similar geography with their neighboring countries, yet these similarities do not reflect the drowning statistics. Research should be targeted to determine the contributing factors for the tremendous differences between Armenia, Georgia, the Russian Federation, and other newly independent states.

\section{THE SPECIAL PROBLEM OF DROWNING IN TURKMENISTAN}

When age-specific male drowning mortality rates are compared, Turkmenistan stands out with an extremely high drowning rate for the 1-4 age group. This rate, 55/100,000 people, is almost 3 times the second highest rate for 1-4 year old males, which is Uzbekistan with 23/100,000 people (Fig. 2). Although the drowning-related mortality rates for this age group are very high in all of the other newly independent states and the Russian Federation, Turkmenistan's rate is alarmingly higher than the rest, and needs investigation. WHO statistics show that the drowning-related mortality rate for this age group has been extremely high in Turkmenistan for the past 20 years.

Except for Turkmenistan, the mortality rates resulting from drowning follow a particular pattern for the newly independent states and Russian Federation, the countries with the highest rates in the WHO Europe region. In Europe, the rate is high for all countries for the 1-4 age group but 


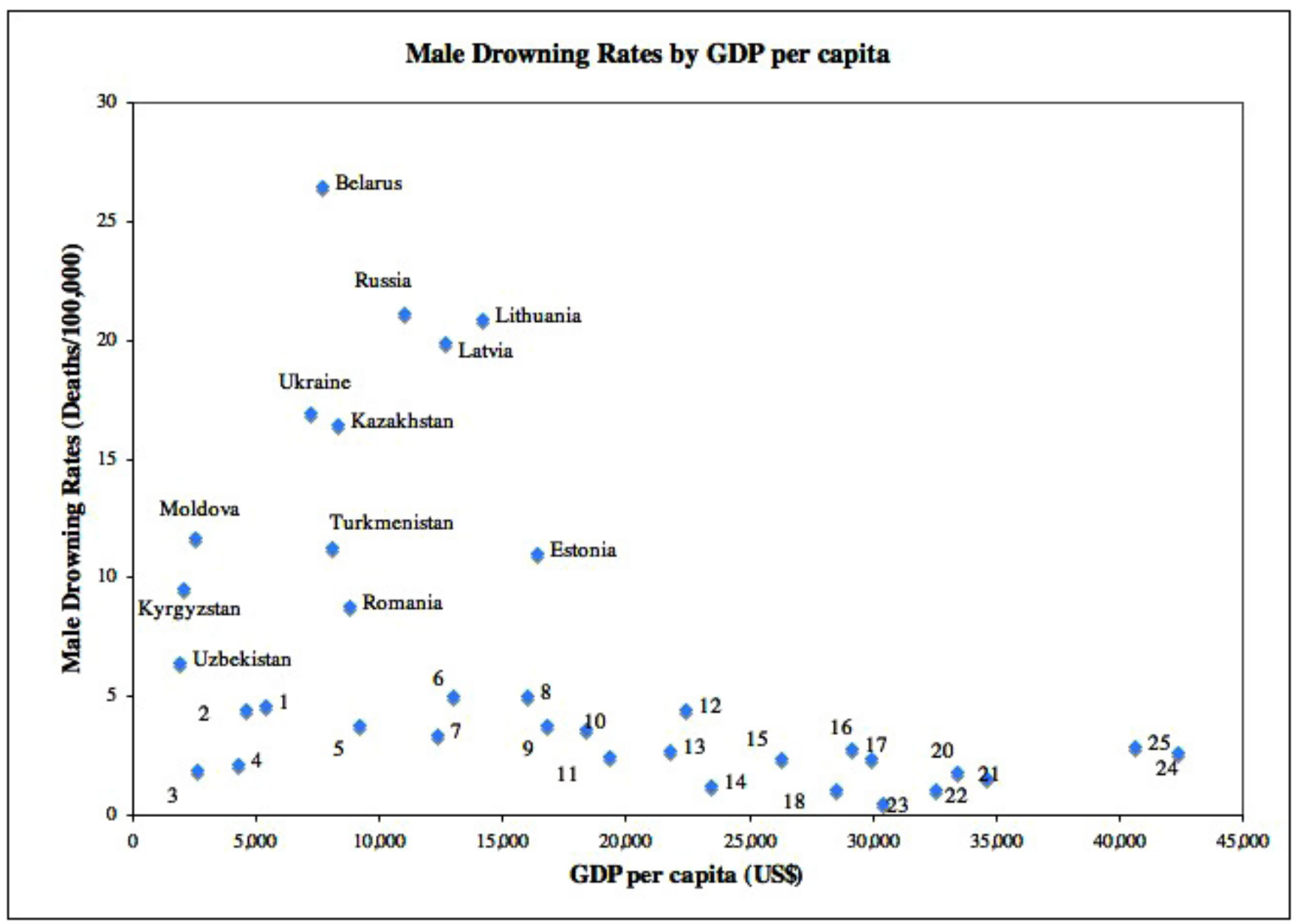

1. Albania 2. Azerbaijan 3. Georgia 4. Armenia 5. Bulgaria 6. Poland 7. Croatia 8. Slovakia 9. Hungary 10. Czech Republic 11. Portugal 12. Greece 13. Slovenia 14. Israel 15. Spain 16. Sweden 17. France 18. Italy 19. Finland 20. Austria 21. Denmark 22. Switzerland 23. United Kingdom 24. Norway 25. Ireland

Fig. (1). Male drowning rates by GDP per capita values for WHO Euro region countries for the year 2000. (Source: World Health Organization Mortality Database. GDP per capita values were obtained from CIA-The World Factbook).

decreases in the 5-14 age group. Thereafter, the drowningrelated mortality rates increase with age group until about 45-54 when the mortality rates peak and then start to decrease. Although the WHO reports that children younger than five years of age have the highest drowning rates worldwide, the rates from this region of the world follow a different pattern. Death due to drowning is more of a problem for adults than for children in these countries.

\section{NEED FOR FURTHER RESEARCH AND POTEN- TIAL FOR PREVENTION}

The importance of drowning as a public health problem is not generally appreciated, in part due to lack of knowledge of its true social and economic burden, and in part due to major underestimation in official statistics. The common public and government perception that drowning deaths occur as a result of human carelessness and there is not much to be done about it must change [2]. This perception hinders the understanding that drowning deaths occur as a result of personal, equipment-related, and environmental factors that can be controlled to a great extent with well-planned interventions. Understanding and assessing the risk factors of drowning in various countries should prove to be of significant value.

Research is urgently needed to estimate the contribution of personal risk factors to drowning related mortality rates in the Newly Independent States and Russian Federation. One major personal risk factor for drowning mortality in adults is alcohol consumption. Howland et al. estimates that, 25 to $50 \%$ of drowning deaths are related to alcohol consumption [3]. Additionally, a study from Finland shows that $52 \%$ of all drownings occurring in Finland between 1987 and 2000 were related to alcohol consumption [4]. Alcohol consumption, which is particularly high in many of the newly independent states and Russian Federation, may be a reason for high mortality rates resulting from drowning in male adults in these countries.

Equipment-related factors should be examined carefully as well. An important risk factor for adult drowning may be the availability and use of safety equipment in fishing and boating practices. Although on the decline, fishing still constitutes a rather large part of the labor economy in many of the newly independent states. For example, fishing consti- 


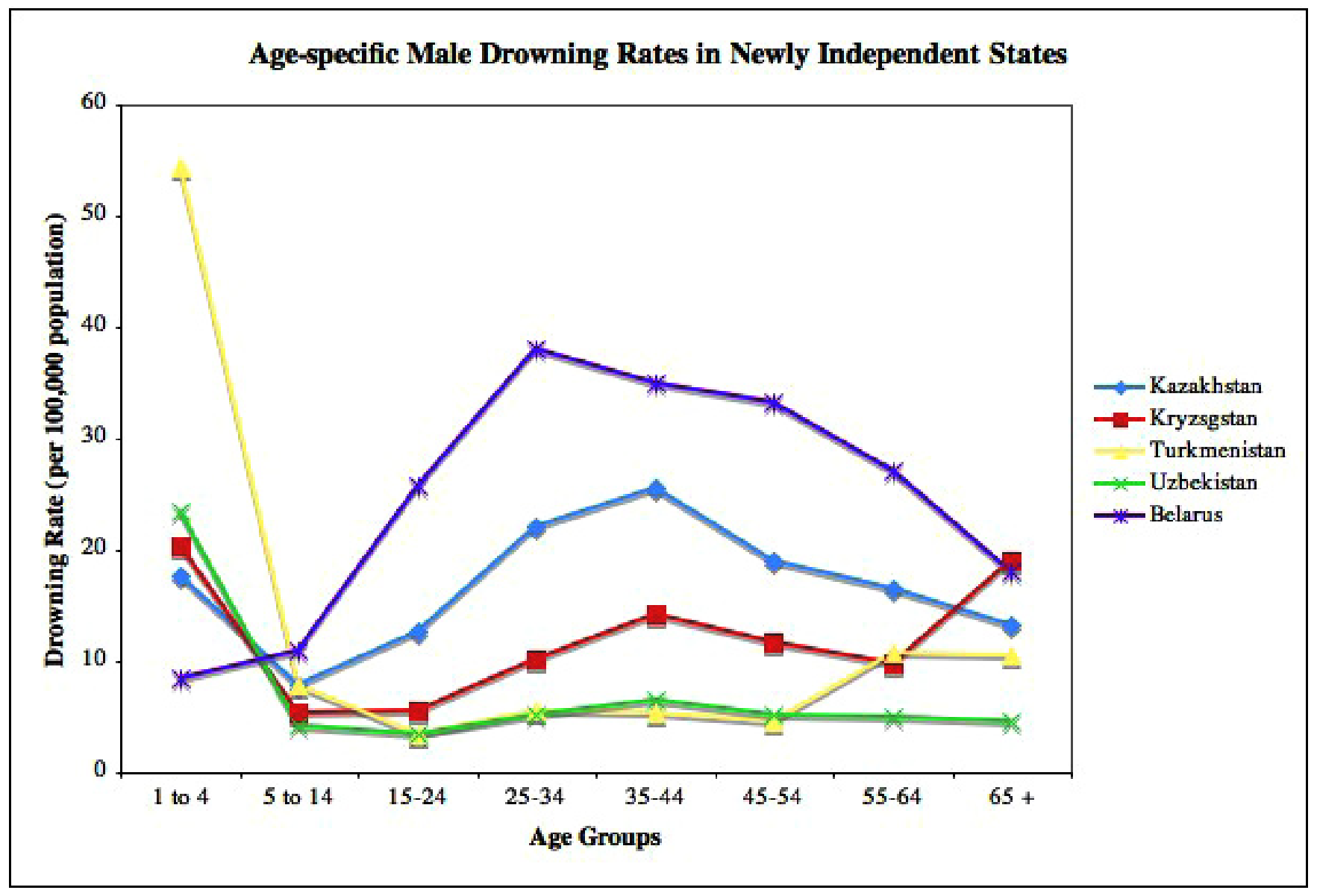

Fig. (2). This figure shows the age specific male drowning rates in Newly Independent States for the year 2000. (Source: WHO Mortality Database).

tuted $20 \%$ of employment in Belarus in 1996 [5]. Fishing is very important in Latvia; there were an estimated 100,000 fishermen in Latvia in 2004 [6]. Interventions aiming at safer fishing practices may prove beneficial in reducing the toll of drownings in these settings.

Further research should be conducted on environmental factors that are important risk factors for drowning. Very high drowning rates for the 1-4 age group in the newly independent states and Russian Federation might be attributed to many environmental factors such as irrigation practices. In Turkmenistan, for example, $88 \%$ of the cultivated area, approximately $1,300,000 \mathrm{ha}$, is covered with irrigation [7]. Uzbekistan, the country with the second highest rate of 1-4 male drownings, has an estimated area of 4,223,000 ha covered with irrigation [8]. The irrigation covers an estimated area of $1,855,200$ ha in Kazakhstan and 1,075,040 ha in Kyrgyzstan [8]. On the other hand, countries with low 1-4 male drowning rates have minimal levels of irrigation practices; Belarus, for example, has an estimated area of 115,000 ha covered with irrigation [8]. Therefore, it is possible that a substantial percentage of the children deaths resulting from drowning occur in irrigation ditches. The feasibility of fencing irrigation ditches in order to prevent child drownings should be explored. Educational interventions aiming to train people about the dangers of irrigation ditches for children and to raise awareness about drowning and approaches to its prevention should prove to be beneficial. Educational inter- ventions should have a component specifically targeting parents about effective supervision for their children.

Statistics from high-income countries, where data is more readily available, reveal that mortality constitutes only a small part of the burden caused by near-drownings. The rate of near drownings resulting in hospitalizations is estimated to be twice the mortality rates due to drowning in both the US and Australia [1]. Specific information about near drowning incidents collected from the Russian Federation and Newly Independent States should be used to determine the social and economic costs of the problem to characterize the true burden of drowning.

More research is needed to determine the contribution of different levels of risk factors on drowning deaths in each of the Newly Independent States and Russian Federation. Systematic collection of information related to drowning will guide public health professionals and policymakers in designing and implementing appropriate effective interventions to ameliorate the burden of drowning in this region.

\section{REFERENCES}

[1] World Health Organization. Drowning Fact Sheet. Violence and Injury Prevention, WHO, Geneva, Switzerland.

[2] Karlson, TA. Injury control and public policy. Clin Rev Environ Control 1992; 22(3/4): 195-241.

[3] Howland J, Hingson R. Alcohol as a risk factor for drownings: a review of the literature (1950-1985). Accid Anal Prev 1988; 20(1): $19-25$. 
[4] Lehto J. Alcohol and the future health of Europe. Addiction 1997; 92(Suppl 1): S91-S96.

[5] Brixiova Z, Volchok V. Labor Market Trends and Institutions in Belarus. William Davidson Institute Working Paper, 2005; Number 777.

[6] Brizga J, Brunenieks J, Belmane I, Vesere R, Bruneniece I. Current Status and Recent Changes in Consumption and Production Patterns in Latvia, 2004; Retrieved at April 9, 2007. www.unep.ch/scoe/archive/baltic/Background\%20report-Latvia_Draft_rev15Jun04.doc.
[7] Food and Agriculture Organization of the United Nations. Irrigation in the Near East Region in Figures. FAO Corporate Document Repository. Rome; 1997

[8] Land and Water Development Division. Global Map of Irrigation Areas by Country. Food and Agriculture Organization of the United Nations (2007) Retrieved at April $9^{\text {th }}$, 2007. http://www.fao. org/ag/agl/aglw/aquastat/irrigationmap/?guidelinks=uz\%2Findex.st $\mathrm{m}$.

(C) Naci and Baker; Licensee Bentham Open.

This is an open access article distributed under the terms of the Creative Commons Attribution License (http://creativecommons.org/licenses/by/2.5/), which permits unrestrictive use, distribution, and reproduction in any medium, provided the original work is properly cited. 